\title{
The assessment of mental disorders in primary health care clinics in the Gaza Strip
}

Abdel-hamid Afana Gaza Community Mental Health Programme, The Gaza Strip, Gaza City, Palestine and Timraz Neda Institute of General Practice and Community Medicine, University of Oslo, Oslo, Norway

\begin{abstract}
Ten primary health care clinics in the Gaza Strip were randomly selected from the five regions that form the Gaza Strip (Southern region, Gaza City, Middle region, KhanYounis and Rafah). The objective of the present study was to investigate the prevalence of mental health problems among patients attending primary health care clinics in the Gaza Strip. Six hundred and sixty-one randomly selected primary health care patients from the five regions were surveyed using the HSCL-25. Seventy-three per cent of patients visiting primary care clinics in the Gaza Strip had psychiatric symptoms consistent with psychiatric disorders. The prevalence of mental health problems among females was higher $(76.8 \%)$ than males $(67 \%)$. Previously married and single patients reported more distressing symptoms than married people. The results also revealed that the prevalence of mental health problems was higher among patients living in refugee camps. Civic status was not associated with mental health problems.
\end{abstract}

Key words: mental disorders; primary health care; socio-demographic variables

\section{Introduction}

Mental disorders constitute one of the most challenging health problems for primary health care professionals in both developed and developing countries (Weiller et al., 1998) and (WHO, 1990). Epidemiological studies have reported significant differences in the prevalence rates of mental disorders among patients attending primary health care clinics (Barrett et al., 1988; Feightner and Worrall, 1990; Goldberg and Huxely, 1980; Shepherd et al., 1981). This may be related to differences in the survey tools used or to the differences in morbidity in the population studied (AlJade and Malkawi, 1997; Fink et al., 1995; Goldberg and Richard, 1996; Portegijs et al., 1996; Robins et al., 1984). In screening for mental disorders, the common use of questionnaires such as the General Health Questionnaire (GHQ), Standardized Psychiatric Interview (SPI) and Hopkins Symptoms Checklist (HSCL-25) has generally estimated that mental disorders account for 20 to $40 \%$

Address for correspondence: Abdel-hamid Afana, Gaza Community Mental Health Programme, PO Box 1049, Gaza City, The Gaza Strip. Email: hamid@gcmhp.net of all illnesses treated in primary health care settings in both developed and developing countries, respectively (Hansson et al., 1994a; Keith, 1993; WHO, 1990). Results from these surveys also indicate that women, unmarried people, unemployed individuals and older patients have higher rates of mental disorders (Fink et al., 1995; Froom et al., 1995; Hansson etal., 1994b; Kramer etal., 1998).

A comparative study among different Nordic primary health care centres using the HSCL-25 as a screening instrument and a standardized psychiatric interview reported that $26 \%$ of the 1281 Scandinavian patients investigated were suffering from mental disorders (Fink et al., 1995). When the HSCL-8D item was used as a subset of HSCL-25 through an exploratory analysis of the data based on factor loadings, it showed that $70.5 \%$ of the patients surveyed had no symptoms, $17 \%$ had one or two symptoms and $13 \%$ of the sample had three to eight symptoms. The HSCL-8D also showed that the most frequently reported symptom was worrying too much about things $(15.7 \%)$, while the least commonly reported symptom was the feeling of worthlessness $(6.2 \%)$.

A study from Jordan using the GHQ-28 as a screening tool showed that the prevalence of men- 
tal disorders among primary health care patients was $61 \%$. The prevalence was highest among patients less than 40 years old $(77 \%)$; and among the 18-29 years age group, the prevalence was $55 \%$. Uneducated, unemployed, and female patients had higher rates of psychiatric disorders than others (Al-Jade and Malkawi, 1997).

The extent of mental health problems in primary health care settings among the Palestinian population is not known, but expected to be high due to overwhelming environmental stressors. Three generations of Palestinians have experienced oppression through exposure to violence, human rights abuses, imprisonment and home demolition. To make matters worse, Palestinians live in a culture that stigmatizes emotional difficulties. It is expected that the prevalence of mental health problems among Palestinian patients attending primary health care clinics would be higher than in Nordic countries where the political situation is relatively peaceful and stable. It is also expected that those living in refugee camps would be associated with a high prevalence of mental health problems.

The purpose of the present study was to investigate the prevalence of mental health problems in primary health care clinics in the Gaza Strip as part of a plan to integrate treatment of mental illness into primary health care settings. Furthermore, this study intends to investigate possible associations between sociodemographic factors (location of residence, age, sex, marital status and employment) and mental health problems. Finally, the purpose remains to compare the prevalence of mental health problems in Gaza with the Nordic countries.

\section{Sample and method}

In the Gaza Strip, primary health care services are largely offered through two main health sectors; the governmental or public sector and the United Nations Relief and Work Agency (UNRWA). Public health services are available both to refugees and original residents who are covered by health insurance. Approximately $40 \%$ of the population are insured (Barghouthi and Daibes, 1996). The remaining uninsured residents receive health services through charitable societies, nongovernmental organizations, and/or the private sector. It is estimated that 33 primary health care clinics are administered by the public sector in the Gaza Strip.
UNRWA offers free primary health care only to registered refugees. UNRWA operates approximately 16 primary health care clinics throughout the Gaza Strip.

Ten primary health care clinics in the Gaza Strip were randomly selected from the five regions that compose the Gaza Strip (the South, Gaza City, Middle region, Khan-Younis and Rafah). Five of these clinics belong to UNRWA health services and five to the public sector.

The sample was drawn from patients coming to consult primary health care physicians in these 10 clinics. All patients aged between 16 and 55 years were included in the study. Patients coming to the clinics due to emergencies and for reasons other than illness (such as for a referral, vaccination, insurance or driver's license examinations, prenatal care, reports) were excluded from the study. Every second patient in each clinic was approached and invited to participate in the study from June to December 1998.

Participation was entirely voluntary and was requested through direct contact, where the purpose of the study was explained. A total of 670 patients were asked to complete the HSCL-25 questionnaire and 661 agreed to participate. For the nine patients who declined to participate in the study, pressure of time was the main reason given. All clarifications about the questions were answered. Written permission to conduct the research was obtained from the UNRWA headquarters and the Palestinian Ministry of Health. Medical consultation data were collected from both patients and physicians by trained interviewers. Of the 661 patients who completed the HSCL-25 questionnaire, $112(17 \%)$ were excluded because they answered less than 23 items of the questionnaire. The mean and the median age of the final study sample of 549 patients was 30 years; female patients represent $57 \%$. The sample distribution with respect to sociodemographic variables is shown in Table 1, indicating that $69 \%$ were refugees and $31 \%$ were original Palestinian residents. Almost all patients from the camps were refugees, while around $40 \%$ of those who came from the villages were refugees, and half of those from cities and from the newly developed areas of the Strip were refugees $(86 \%)$. Forty-three per cent of patients from the camps were 16-24 years old (Table 1).

The HSCL has several versions of different 
Table 1 Socio-demographic characteristics of patients in each residential area

\begin{tabular}{|c|c|c|c|c|c|c|c|c|c|c|}
\hline & \multicolumn{2}{|c|}{ Total } & \multicolumn{2}{|c|}{ Camp } & \multicolumn{2}{|c|}{ Village } & \multicolumn{2}{|c|}{ City } & \multicolumn{2}{|c|}{ New areas } \\
\hline & $N$ & $\%$ & $N$ & $\%$ & $N$ & $\%$ & $N$ & $\%$ & $N$ & $\%$ \\
\hline \multicolumn{11}{|l|}{ Civic status } \\
\hline Original residents & 171 & 31.2 & 15 & 6.5 & 79 & 60.3 & 71 & 50.0 & 16 & 14.0 \\
\hline Refugees & 378 & 68.8 & 217 & 93.5 & 52 & 39.7 & 71 & 50.0 & 38 & 88.3 \\
\hline \multicolumn{11}{|l|}{ Gender } \\
\hline Male & 235 & 42.8 & 101 & 43.5 & 50 & 38.2 & 61 & 43.0 & 23 & 53.5 \\
\hline Female & 314 & 57.3 & 132 & 56.9 & 81 & 61.8 & 81 & 57.0 & 20 & 46.5 \\
\hline \multicolumn{11}{|l|}{ Age } \\
\hline $16-24$ & 204 & 37.5 & 100 & 43.3 & 43 & 33.3 & 39 & 27.7 & 22 & 51.2 \\
\hline $25-34$ & 146 & 26.8 & 60 & 26.0 & 25 & 19.4 & 51 & 36.2 & 10 & 23.3 \\
\hline $35+$ & 194 & 35.7 & 71 & 30.7 & 61 & 47.3 & 51 & 36.2 & 11 & 25.6 \\
\hline \multicolumn{11}{|l|}{ Marital status } \\
\hline Married & 355 & 64.7 & 138 & 59.5 & 93 & 71 & 99 & 69.7 & 25 & 58.1 \\
\hline Not married & 194 & 35.4 & 95 & 40.9 & 38 & 29 & 43 & 30.3 & 18 & 41.9 \\
\hline \multicolumn{11}{|l|}{ Occupation } \\
\hline House wife & 222 & 40.6 & 92 & 39.8 & 55 & 43.5 & 64 & 45.1 & 9 & 21.4 \\
\hline Unemployed & 112 & 20.4 & 56 & 24.2 & 314 & 13 & 19 & 19.0 & 356 & 28.6 \\
\hline Laborers & 63 & 11.5 & 25 & 10.8 & 315 & 15.3 & 14 & 9.9 & 4 & 9.5 \\
\hline Office work & 92 & 16.8 & 42 & 18.2 & 23 & 17.6 & 18 & 12.7 & 9 & 21.4 \\
\hline Student & 60 & 11.0 & 19 & 8.2 & 14 & 10.7 & 19 & 13.4 & 8 & 19 \\
\hline \multicolumn{11}{|l|}{ Education } \\
\hline No school & 37 & 6.8 & 16 & 6.9 & 11 & 8.4 & 9 & 6.3 & 1 & 2.3 \\
\hline Primary & 114 & 20.7 & 38 & 16.3 & 30 & 22.8 & 39 & 27.5 & 7 & 16.3 \\
\hline Preparatory & 188 & 34.3 & 83 & 35.8 & 45 & 34.4 & 46 & 23.4 & 14 & 32.6 \\
\hline Secondary and higher & 210 & 38.3 & 96 & 41.4 & 45 & 34.4 & 48 & 33.8 & 21 & 48.8 \\
\hline
\end{tabular}

lengths (90-16 items) and has been used in a wide range of primary health care settings (Vaeroy and Merskey, 1997). The HSCL-25 was used as a screening instrument in the present study in order to detect mental health problems (Derogatis et al., 1974; Joukamaa et al., 1994). HSCL-25 has been established as a valid and reliable measure of psychiatric symptoms, in particular, screening of anxiety and depression experienced by the patient during the preceding week. Translated versions of the HSCL-25 have been widely used (Hansson et al., 1994a; Joukamaa et al., 1995; Nettelbladt et al., 1993). In the present study, we prepared a translation of the HSCL-25 questionnaire in Arabic, as well as completing a back translation into English by a second resource person. This was done to identify misinterpretations of the questionnaire as compared with the original English version. The back-translated questionnaire was compared with the original material and discrepancies in terminology and phrasing corrected. Pilot testing was carried out, and the Cronbach alpha reliability correlation coefficient was 0.77 . On the HSCL-25 form, patients recorded their own estimates of symptom severity present during the past week on a four-point scale ranging from 1 ('not at all') to 4 ('extremely'). Responses were summed and divided by the number of the answers. The patient was considered in need of psychiatric intervention if the mean rating score was over 1.75 (Borgquist et al., 1993; Hansson et al., 1994a). The patients were also asked for information regarding demographic data such as age, sex, marital and civil status, living situation, and educational level. In order to compare these data with the Nordic study, the constructed version of HSCL-8D was used. It is a reduced version of HSCL-25, from 25 to eight items (Fink et al., 1995).

\section{Statistical methods}

Data analyses were completed using the Statistical Programme Package for Social Science (SPSS) 
software. Associations between selected independent variables and the outcome cases/noncases with mental health problems were investigated in bivariate analysis and tested for statistical significance by chi-square test. In conditional logistic regression analyses, crude and adjusted odd ratios (OR) were used as a measure of association. The level of statistical significance was set to $P \leq 0.05$ (95\% confidence intervals).

\section{Results}

\section{Prevalence of mental health problems}

Overall prevalence of mental health problems among Palestinian primary health care patients was $73 \%$, and higher among females (76.8\%) than males $(67 \%), P=0.013$ (Table 2).
With respect to marital status, previously married and single individuals demonstrated a higher prevalence of mental health problems than married patients $(P=0.003)$. Patients living in camps had a higher prevalence of mental health problems than those living in other places $(P=0.03)$. On the other hand, there were no significant differences between refugees and original residents of the Gaza Strip $(P=0.79)$, and likewise between the different educational levels and age groups $(P=0.08)$.

Based on the HSCL-8D items, the most commonly reported symptom in both the current and the Nordic study, was 'worrying too much about things' (Table 3). The present study showed that $45 \%$ of the patients felt that 'everything is an effort' compared with $16 \%$ among the Nordic patients $(P=<0.002)$, while $27 \%$ of the Palestinian patients felt 'nervous' compared with $13 \%$ of

Table 2 Sociodemographic variables and psychiatric caseness according to HSCL-25 score ${ }^{\text {a }}$

\begin{tabular}{|c|c|c|c|c|c|}
\hline & \multicolumn{2}{|c|}{ Noncase HSCL $<1.75$} & \multicolumn{2}{|c|}{ Cases HSCL $\geq 1.75$} & \multirow{2}{*}{$\begin{array}{l}\chi^{2} \\
P \text { value }\end{array}$} \\
\hline & $N$ & $\%$ & $N$ & $\%$ & \\
\hline All & 150 & 27.3 & 399 & 72.7 & \\
\hline $\begin{array}{l}\text { Civic status } \\
\text { Original resident } \\
\text { Refugee }\end{array}$ & $\begin{array}{r}48 \\
102\end{array}$ & $\begin{array}{l}28.1 \\
27.0\end{array}$ & $\begin{array}{l}123 \\
276\end{array}$ & $\begin{array}{l}71.9 \\
73.0\end{array}$ & 0.791 \\
\hline $\begin{array}{l}\text { Gender } \\
\text { Male } \\
\text { Female }\end{array}$ & $\begin{array}{l}77 \\
73\end{array}$ & $\begin{array}{l}32.3 \\
23.2\end{array}$ & $\begin{array}{l}158 \\
241\end{array}$ & $\begin{array}{l}67.2 \\
76.8\end{array}$ & 0.013 \\
\hline $\begin{array}{l}\text { Education } \\
\text { No school } \\
\text { Primary school } \\
\text { Unfinished secondary school } \\
\text { Secondary and higher }\end{array}$ & $\begin{array}{r}8 \\
33 \\
41 \\
68\end{array}$ & $\begin{array}{l}21.1 \\
29.2 \\
21.8 \\
32.4\end{array}$ & $\begin{array}{r}30 \\
80 \\
147 \\
142\end{array}$ & $\begin{array}{l}78.9 \\
70.18 \\
78.2 \\
67.6\end{array}$ & 0.088 \\
\hline $\begin{array}{l}\text { Age } \\
16-24 \\
25-43 \\
35 \text { above }\end{array}$ & $\begin{array}{l}47 \\
38 \\
61\end{array}$ & $\begin{array}{l}23.0 \\
27.2 \\
31.4\end{array}$ & $\begin{array}{l}157 \\
107 \\
133\end{array}$ & $\begin{array}{l}77.0 \\
72.8 \\
68.6\end{array}$ & 0.169 \\
\hline $\begin{array}{l}\text { Marital status } \\
\text { Married } \\
\text { Single } \\
\text { Previously married }\end{array}$ & $\begin{array}{r}113 \\
33 \\
2\end{array}$ & $\begin{array}{r}31.9 \\
20.1 \\
9.5\end{array}$ & $\begin{array}{r}241 \\
139 \\
19\end{array}$ & $\begin{array}{l}68.1 \\
79.9 \\
90.5\end{array}$ & 0.003 \\
\hline $\begin{array}{l}\text { Living place } \\
\text { Camp } \\
\text { Village } \\
\text { City } \\
\text { New areas }\end{array}$ & $\begin{array}{l}48 \\
45 \\
44 \\
12\end{array}$ & $\begin{array}{l}21.1 \\
43.4 \\
31.0 \\
27.9\end{array}$ & $\begin{array}{r}183 \\
86 \\
98 \\
31\end{array}$ & $\begin{array}{l}78.9 \\
65.6 \\
69.0 \\
72.1\end{array}$ & 0.033 \\
\hline
\end{tabular}

${ }^{\mathrm{a} C h i-s q u a r e ~ t e s t ~ f o r ~ d i f f e r e n c e s ~ b e t w e e n ~ c a t e g o r i e s . ~}$ 
Table 3 The HSCL-8D symptoms compared with the Nordic study

\begin{tabular}{|c|c|c|c|c|c|}
\hline \multirow[t]{2}{*}{ Symptoms } & \multicolumn{2}{|c|}{$\begin{array}{l}\text { Nordic frequency of symptoms } \\
\qquad(n=1281)\end{array}$} & \multicolumn{2}{|c|}{$\begin{array}{l}\text { Palestinian frequency of symptoms } \\
\qquad(n=549)\end{array}$} & \multirow[t]{2}{*}{$P$ value } \\
\hline & $n$ & $\%$ & $n$ & $\%$ & \\
\hline Worrying & 201 & 15.7 & 190 & 17.5 & 0.000 \\
\hline Everything is an effort & 207 & 16.2 & 273 & 44.7 & 0.002 \\
\hline Nervousness & 169 & 13.2 & 164 & 26.8 & 0.000 \\
\hline Depressive mood & 144 & 11.2 & 107 & 17.5 & 0.043 \\
\hline Anxious & 108 & 8.4 & 80 & 13.1 & 0.003 \\
\hline Hopelessness & 114 & 8.9 & 131 & 21.4 & 0.000 \\
\hline Panic attacks & 83 & 6.5 & 35 & 5.7 & 0.60 \\
\hline Low confidence & 79 & 6.2 & 45 & 7.4 & 0.85 \\
\hline
\end{tabular}

the Nordic patients $(P=<0.000)$. The lowest symptom reported in both the Palestinian and the Nordic populations was a 'feeling of low confidence' ( 7 and $6 \%$, respectively, $P=>0.85$ ). The study also showed that $14 \%$ of the Palestinian sample had no symptoms compared with $70 \%$ in the Nordic sample, while $30 \%$ had one or two symptoms compared with $17 \%$ among Nordic patients and $54 \%$ have thee to eight symptoms compared with $13 \%$ among Nordic patients.

The study also indicated that refugees living in villages showed a lower prevalence of mental health problems than original residents, $P=0.02$ (Table 4). Logistic regression analyses, controlling for selected independent variables (Table 5) showed that being single as compared with being married, living in refugee camps as compared with living in a village or city, were frequently associated with mental health problems. Sex, age, civic status or education levels (except unfinished secondary school) were not associated with mental health problems.

\section{Discussion}

Consulting primary health care clinics is a common way for people with mental health problems to seek support. As far as the authors are aware, no previous studies of the prevalence of mental health problems among patients attending primary health care clinics have been conducted in Palestine. The present study, among the first of its kind in the Gaza Strip indicates that mental health problems are common, affecting $73 \%$ of patients who receive nonemergency treatment from primary health care centres in the Gaza Strip. Women, people who were previously married and people living in refugee camps present the highest prevalence of mental ill-health symptoms.

With respect to representation, the population distribution according to civic status and place of living was approximately the same in the study sample and total population of Gaza (Barghouthi and Diabes, 1996). Among the total population of Gaza, $44 \%$ live in cities, $16 \%$ in villages, and $40 \%$

Table 4 Psychiatric caseness (HSCL case $\geq 1.75$ ) by and place of living and civic status

\begin{tabular}{|c|c|c|c|c|}
\hline \multirow[t]{2}{*}{ Civic status } & \multicolumn{4}{|c|}{ Place of living } \\
\hline & Refugee camps & Villages & Cities & New areas \\
\hline \multirow[t]{2}{*}{ Refugees } & 171 & 28 & 48 & 28 \\
\hline & $78.8 \%$ & $53.8 \%$ & $67.6 \%$ & $75.7 \%$ \\
\hline \multirow[t]{2}{*}{ Original residence } & 12 & 58 & 50 & 3 \\
\hline & $80.0 \%$ & $75.4 \%$ & $70.4 \%$ & $50.0 \%$ \\
\hline$P$-value & 1.00 & 0.025 & 0.86 & 0.33 \\
\hline
\end{tabular}


Table 5 Association between mental health problems (HSCL-25, cut-off $\geq 1.75$ ) and selected independent variables

\begin{tabular}{|c|c|c|}
\hline Independent variables & $\begin{array}{l}\text { Adj. ORa } 95 \% \mathrm{Cl} \\
\text { lower-upper }\end{array}$ & $\begin{array}{l}P \\
\text { value }\end{array}$ \\
\hline $\begin{array}{l}\text { Place of living } \\
\text { Refugee camp }\end{array}$ & Reference & 0.031 \\
\hline Village & $0.45(0.26-0.79)$ & 0.005 \\
\hline City & $0.53(0.31-0.090)$ & 0.018 \\
\hline New areas & $0.72(0.34-1.54)$ & 0.398 \\
\hline & \multirow[t]{3}{*}{0.06} \\
\hline Female & Reference & \\
\hline & $0.69(0.46-1.03)$ & \\
\hline & \multirow[t]{3}{*}{0.289} \\
\hline Original residence & Reference & \\
\hline & $0.79(0.47-1.25)$ & \\
\hline & \multirow[t]{2}{*}{0.150} \\
\hline Secondary and higher & Reference & \\
\hline No school & $1.73(0.72-4.16)$ & 0.221 \\
\hline Primary school & $1.34(0.80-2.26)$ & 0.265 \\
\hline Unfinished secondary & $1.69(1.05-2.71)$ & 0.030 \\
\hline \multicolumn{2}{|l|}{ Marital status } & \multirow[t]{2}{*}{0.029} \\
\hline Married & Reference & \\
\hline Single & $2.04(1.09-3.79)$ & 0.024 \\
\hline Previously married & $3.16(0.71-14.10)$ & 0.131 \\
\hline \multicolumn{2}{|l|}{ Age } & \multirow[t]{2}{*}{0.706} \\
\hline 35 years above & Reference & \\
\hline $16-24$ years & $1.29(0.68-2.43)$ & 0.433 \\
\hline $25-34$ years & $1.12(0.59-2.10)$ & 0.736 \\
\hline
\end{tabular}

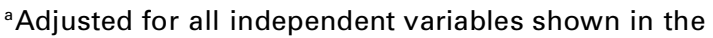
table.

in refugee camps. Refugees constitute more than $75 \%$ of the total population, with $56 \%$ living in refugee camps, the remaining $44 \%$ living in the cities, villages and the so-called new areas. Whereas the proportion of refugees in the sample is $69 \%$, the majority of them live in refugee camps $(58 \%)$, and $42 \%$ live in cities, villages and new areas. These figures indicate that the present sample is reasonably representative of the population of Gaza. However, the aforementioned prevalence figures of mental health problems cannot be generalized to the entire population. It is, however, likely that these findings are valid for patients attending primary health care clinics in the Gaza Strip.

As expected, the prevalence of mental health problems is higher in Gaza than in the Nordic countries (Fink et al., 1995), where the prevalence was lower at $26 \%$. However, the high prevalence among Palestinians is in accordance with a Jordanian study, which showed that the prevalence of mental disorders was $61 \%$. Furthermore, the Jordanian study indicated that patients more than 40 years of age had the highest rate of mental disorders $(77 \%)$, than those aged $18-29$ years $(55 \%)$ as well as those aged 30-39 years (56\%). Findings reveal that among those with limited education, higher rates of mental disorders were evidenced $(81 \%)$, as compared with those with a high school diploma (48\%). The prevalence of mental disorders was higher among those who are unemployed than employed, 73 and $47 \%$, respectively. It should be mentioned that considerable proportions of the population in northern Jordan are refugees from Palestine. In part, this may explain the similarity in prevalence rates between Gaza and the Jordanian study (Al-Jade et al., 1997). The reported associations between mental health problems and variables of sex, age and marital status were similar to the Nordic study.

The HSCL-25 is suitable for psychiatric assessment in primary health care settings and this assessment tool generally shows high correlation with clinically assessed depression (Froom et al., 1995). Lavik et al. (1999) carried out a validation study comparing the results of HCSL-25 with the Global Assessment of Function (GAF) and the Global Rating on the BPRS in a refugee population in Norway (the majority were from the Middle East). They reported that the HCSL-25 predicted mental health problems in the multicultural subject population. In the present study, a panel of experts evaluated the validity of HCSL-25. The questionnaires were discussed with five local experts to assess its relevance to Arab culture. The only difficulty in applying the questionnaire was that the patients felt embarrassed to answer the item about sex.

The differences in prevalence between the current study and the Nordic study may be related to differences in environmental and stress factors experienced by the patients. The Palestinian population is living through a long history of Israeli occupation and violence. Additionally, the Intifada, which started in 1987 as a mass expression of feelings and rejection of the Israeli occupation has altered the daily lives of Palestinians. The price of the Intifada has proved to be high - houses were demolished, curfews imposed, that sometimes 
lasted up to 40 days, isolated families and friends, and night raids created fertile ground for stressrelated problems among the population (Khamis, 1993; Qouta and El Sarraj, 1993; Qouta et al., 1997a). The psychosocial consequences of imprisonment and torture of the Palestinians in Israeli gaols correspondingly created significant stressrelated symptoms (El Sarraj et al., 1996; Qouta et al., 1997b).

Our data indicate that women report a higher prevalence of mental disorders than men, which is in accordance with several epidemiological studies (Kessler et al., 1985; Kramer and Garralda, 1998; Piccinelli and Simon, 1997). Among stress factors particularly relevant to women, the contextual profile of life in Palestinian society means that women are living in a patriarchal community where men have more power and authority (Heiberg and Geir, 1994). Women are often exposed to a great deal of domestic violence and abuse from their husbands and blood relatives. A study by Qouta et al. (1999) indicated that 25\% of women in Gaza were exposed to domestic abuse once in their childhood. Previously married people, especially females, face complex cultural constraints such as difficulty in getting remarried, inability to live independently, and poor prospects of finding jobs. Studies indicate that employed women are less prone to mental health problems than housewives (Hesbacher et al., 1980).

During the Intifada, a 'collectivist' style of relating between individuals and their community existed; individuals put aside self-interest and obeyed the will of the group (Dwairy and De Gruyter, 1998) and (Mirowsky and Ross, 1989). They often renounced the losses of their beloved sons, husbands, brothers and fathers. When the Intifada subsided and was terminated by the Declaration of Peace Principles between Palestinians and Israelis, the high expectations and hopes that people had for the peace process were not subsequently realized. This outcome opened wounds created by the loss of important family members and friends. The process of looking back at the losses of loved ones might increase the likelihood of stress-related problems.

The study also indicates that the refugees living in camps have a higher prevalence of mental health problems, than those living in other areas. This variance may be explained by the bad economic situation, overcrowded housing, poor infrastructure and public health problems of the camps. In addition, those refugees living in camps have suffered more than other segments of the Palestinian population during the Intifada. They were exposed to a number of harmful consequences, at a far more frequent rate than those who lived in cities or villages. These included imprisonment, shooting by the Israelis, night raids, and house demolition. One should consider that those who moved from the camps were the wealthier and most likely, healthier individuals, with greater self-esteem and higher personal resources.

\section{Conclusion}

The study has revealed that the prevalence of mental health problems among Palestinians attending primary health care clinics in the Gaza Strip is high in comparison with other nations. These results indicate a serious need for genuine efforts toward the integration of mental health treatment into primary health care settings. In order for such systemic change to meet the needs of all patients, greater emphasis on the total, whole person is a priority. Such an agenda is useful at individual and community levels. It could be argued that when people live in circumstances where there are political, social and economic hardships such as the population in Gaza, they would be predisposed to develop mental ill-health symptoms, which need urgent interventions at professional, political, environmental and social levels.

\section{References}

Al-Jade, H. and Malkawi, A. 1997: Prevalence, recognition and management of mental disorders in primary health care in Northern Jordan. Acta Psychiatr Scand 96, 31-35.

Barghouthi. M. and Daibes, I. 1996: Infrastructure and health services in the Gaza Strip. Retrieved from: www.hdip. org/publication/gzsum96.html.

Barrett, J.E., Barrett, J.A., Orman, T. and Gerber, P. 1988: The prevalence of psychiatric disorders in a primary care practice. Arc Gen Psychiatry 45, 1100-109.

Borgquist, L., Hansson, L., Nettelbladt, P., Nordstorm, G. and Lindelow, G. 1993: Perceived health and high consumers of care: a study of mental health problems in a Swedish primary health care district. Psychological Medicine 23, 763-70.

Derogatis, L., Lipman, R., Rickels, K., Uhlenhuth and Covi, L. 1974: The Hopkins Symptoms Checklist (HSCL): a measure of primary symptoms dimensions. Psychological Measurement in Psychopharmacology Pharmacopsychiat 7, 79-110. 
Dwairy, M. and de Gruyter, A. 1998: Cross-Cultural Counseling: the Arab-Palestinian Case. New York: Haworth Press.

EI Sarraj, E., Punamaki, R.L., Suhaile, S. and Summerfield, D. 1996: Experiences of torture and ill treatment and posttraumatic stress disorder: symptoms among Palestinian political prisoners. Journal of Traumatic Stress 9, 595-605.

Feightner, J.W. and Worrall, G. 1990: Early detection of depression by primary care physicians. Can Med Assoc Journal 142, 1215-20.

Fink, P., Jensen, J., Borgquist, L., Brevik, J.I., Dalgard, O.S., Sandager, I., Engberg, M., Hansson, L., Holm, M., Joukamaa, M., Karlsson, H., Lethinen, V., Nettelbladt, P., Nordstrom, G., Stefansson, C.G. and Sorensen, L. 1995: Psychiatric morbidity in Primary Public Health Care: a Nordic multicentre investigation Part 1: method and prevalence of psychiatric morbidity. Acta Psychiatric Scand 92, 409-18.

Froom, J., Hideyasu, A., Doron, H., Yoshio, M. and Galambos, N. 1995: Depressive disorders in three primary care populations: United States, Israel, and Japan. Family Practice 12, 274-77.

Goldberg, G. and Huxely, P. 1980: Mental illness in the community: the pathway to psychiatric care. London: Tavistock.

Goldberg, D. and Richard, G. 1996: Implications of the World Health Organisation study of mental illness in general health care for training primary care staff. British Journal of General Practice 46, 483-85.

Hansson, L., Nettelbladt, P., Borgquist, L. and Nordstrom, G. 1994a: Screening for psychiatric illness in primary care: a cross-sectional study in a Swedish health district. Psychiatry Psychiatr Epidemiol 29, 83-87.

Hansson, L., Borgquist, L. Nettelbladt, P. and Nordstrom, G. 1994b: The course of psychiatric illness in primary care patients: a 1-year follow up. Soc Psychiatry Psychiatr Epidemiol 29, 1-7.

Heiberg, M. and Geir, O. 1994: Palestinian society in Gaza, West Bank and Arab Jerusalem: a survey of living conditions. FAFO-report 151. Ramallah, ADWA.

Hesbacher, P.T., Rieckels, K., Morris, R.J., Newman, H. and Rosenfeld, H. 1980: Psychiatric illness in family practice. $J$ Clin Psychiatry 4, 6-10.

Joukamaa, M., Lehtinen, V., Karlsson, H. and Rouhe, E. 1994: SCL-25 and recognition of mental disorders reported by primary health care physicians. Acta Psychiatric Scand 89, 320-23.

Joukamaa, M., Lehtinen, V. and Karlsson, H. 1995: The ability of general practitioners to detect mental disorders in primary health care. Acta Psychiatr Scand 91, 52-6.

Keith, L. 1993: Depression and anxiety among Afro-Caribbean general practice attenders in Britain. The International Journal of Social Psychiatry 39, 1-9.

Kessler, L., Cleary, P. and Burke, J. 1985: Psychiatric disorders in primary care: results of a follow up study. Arch Gen Psychiatry 42, 583-87.
Khamis, V. 1993: Posttraumatic stress disorder among the injured of the Intifada. Journal of Traumatic Stress 6, 555-9.

Kramer, T. and Garralda, P. 1998: Psychiatric disorders in adolescents in primary care. British Journal of Psychiatry 173, 508-13.

Lavik, N.J., Laake, P., Hauff, E. and Solberg, O. 1999: The use of self-reports in psychiatric studies of traumatized refugees: Validation and analysis of HSCL-25. Nord J Psychiatry, 53, 17-20.

Mirowsky, J. and Ross, C.E. 1989: Social causes and psychological distress. New York: Aldine de Gruyter.

Nettelbladt, P., Hansson, L., Stefansson, C.G., Borgquist, L. and Nordstorm, G. 1993: Test characteristics of the Hopkins Symptoms Check List-25 (HSCL-25) in Sweden, using the Present State Examination (PSE-9) as a caseness criterion. Social Psychiatry and Psyciatric Epidemiology Journal 28, 130-33.

Piccinelli, M. and Simon, G. 1997: Gender and cross-cultural differences in somatic symptoms associated with emotional distress: an international study in primary care. Psychological Medicine 27, 433-44.

Portegijs, P.J., van der Horst, F.G., Proot, I.M., Kraan, H.F., Gunther, N.C. and Knottnerus, J.A. 1996: Somatisation in frequent attenders of general practice. Soc Psychiatry Epidem 31, 29-37.

Qouta, S. and El Sarraj, E. 1993: The level of anxiety in Gaza: before and after the Intifada. Egyptian Psychological Studies, 3, 1-11.

Qouta, S., Punamaki, R,L. and El Sarraj, E. 1997a: House demolition and mental health: victims and witnesses. Journal of Social Distress and Homelessness 6, 203-11.

Qouta, S., El Sarraj, E. and Punamaki, R.L. 1997b: Prison experiences and coping styles among Palestinian men: Peace and conflict. Journal of Peace Psychology 3, 9-36.

Qouta, S., El Massri, M. and Timraz, N. 1999: The prevalence of mental disorders in the Palestinian community in Gaza. GCMHP newsletter, Gaza, Palestine.

Robins, L.N., Helzer, J.E., Weissman, M.M. et al. 1984: Lifetime prevalence of specific psychiatric disorders in three sites. Archives of General Psychiatry 41, 949-58.

Shepherd, M., Cooper, B., Brown, A.C. and Kalton, G. 1981: Psychiatric illness in general practice (2nd edn.). Oxford: Oxford University Press.

Vaeroy, H. and Merskey, H. 1997: The prevalence of current major depression and dysthymia in a Norwegian general practice. Acta Psychiatr Scan 95, 324-28.

Weiller, E., Bisserbe, J., Maier, W. and Lecrubier, Y. 1998: Prevalence and recognition of anxiety syndromes in five European primary health settings: a report from the WHO study on psychological problems in General Health Care. British Journal of Psychiatry 173 (Suppl. 34), 18-23.

World Health Organization. 1990: The introduction of a mental health component into primary health care. Geneva: WHO. 